\title{
NECESSIDADES HÍDRICAS DE CITROS E MACIEIRAS A PARTIR DA ÁREA FOLIAR E DA ENERGIA SOLAR ${ }^{1}$
}

\author{
ANDRÉ BELMONT PEREIRA², NILSON AUGUSTO VILLA NOVA ${ }^{3}$, \\ ADRIANE THEODORO ALFARO ${ }^{4}$
}

RESUMO - A energia solar é a fonte primária para a fotossíntese e a transpiração vegetal para que uma cultura expresse seu potencial produtivo em um dado local. O método proposto neste estudo pretende facilitar o cálculo do volume de água (litros/planta/dia) necessário para uma irrigação localizada com o mínimo desperdício possível em pomares cítricos e de macieiras, utilizando-se de dados usualmente disponíveis, tais como área foliar, densidade de fluxo de radiação solar global, saldo de radiação e déficit de saturação de vapor médio diário do ar. Considerando-se que a irrigação localizada consome bem menos água do que o sistema de aspersão, e que a outorga de água para irrigação está cada vez mais limitada, tal estudo vem a ser certamente de grande importância para assegurar a autossustentabilidade da agricultura irrigada, especialmente em regiões áridas e semiáridas. Foram utilizados neste trabalho, para desenvolvimento da metodologia proposta, dados de fluxo de seiva medidos através do método de fluxo de calor, em pomar de lima-ácida-Tahiti com área foliar de 48 e $99 \mathrm{~m}^{2}$, bem como em pomar de macieiras com área foliar aproximada de 5; 8; 9; 11; $16 \mathrm{e}$ $21 \mathrm{~m}^{2}$. Os resultados obtidos indicaram que a metodologia proposta, baseada na habilidade das plantas em converter energia solar fixada em água transpirada, mostrou-se viável para avaliar a lâmina de irrigação de plantas cítricas e macieiras nas localidades estudadas.

Termos para indexação: irradiância solar, saldo de radiação, modelagem, consumo de água, espécies frutíferas.

\section{WATER REQUIREMENTS OF CITRUS AND APPLE TREES AFFECTED BY LEAF AREA AND SOLAR ENERGY}

\begin{abstract}
Solar energy is the primary source for photosynthesis and transpiration in such a way as to assure the expression of the crop yield potential at a given site. The current methodology aims to ease the calculation of the water amount (liters/plant/day) necessary for a localized irrigation scheduling with a minimal loss possible at both citrus and apple trees orchards by means of usual available data, such as leaf area, global solar radiation flux density, net radiation and air daily mean steam saturation deficit. Taking into account that the localized irrigation system takes up far less water than sprinkler systems and also that the grant of water for irrigation is becoming more and more limited, such a work certainly comes to be of a great importance to assure the sustainability of the irrigated agriculture, especially at both arid and semi-arid regions. For the development of the proposed methodology a data set of sap flux measured by means of the heat flux approach in a citrus orchard, cultivar Tahiti, with leaf areas of 48 and $99 \mathrm{~m}^{2}$, as well as in apple trees with leaf areas roughly of 5, 8, 9, 11, 16 and $21 \mathrm{~m}^{2}$ was used herein. The obtained results revealed that it is rather feasible to estimate the amount of irrigation water throughout the whole citrus and apple trees cycle by means of the criterion based on the physiological variable input, which expresses the ability of the plants to converting solar energy into water taken up in the transpiration process at the sites in study.
\end{abstract}

Index terms: solar irradiance, net radiation, modeling, water consumption, fruit trees.

\footnotetext{
'(Trabalho 218-08). Recebido em: 21-08-2008. Aceito para publicação em: 22-06-2009.

${ }^{2}$ Prof. Associado do Depto de Ciência do Solo e Engenharia Agrícola - UEPG - Ponta Grossa-PR. E-mail: andre.pereira@pq.cnpq.br ${ }^{3}$ Prof. Associado do Depto de Ciências Exatas - ESALQ/USP - Piracicaba-SP. E-mail: navnova@esalq.usp.br. Bolsista em Produtividade - CNPq.

${ }^{4}$ Mestranda do PPG em Agronomia da UEPG, Profa. Assistente da Faculdade de Agronomia do CESCAGE - Ponta Grossa-PR. Email: adrianealfaro@cescage.edu.br
} 


\section{INTRODUÇÃO}

Embora o Brasil se destaque como maior produtor mundial de citros e maior produtor e exportador de suco concentrado congelado de laranja, deve-se considerar a grande diversificação agroclimática brasileira e suas condições particulares de cultivo para obtenção de elevadas produtividades. Essas condições compreendem a multiplicidade de ambientes, nos quais se verifica desde a ocorrência de geadas ocasionais ou frequentes, até estresses hídricos ou térmicos, implicando múltiplas floradas com crescimento e maturação irregulares dos frutos (Coelho et al., 2004).

A energia solar é a fonte primária para a atividade fotossintética e também para a transpiração das plantas em determinada localidade climática. $\mathrm{O}$ aporte de água para as frutíferas temperadas e tropicais é necessário para assegurar a floração, o pegamento e o crescimento dos frutos. A lâmina de irrigação aplicada nas diferentes etapas fenológicas da cultura afeta a qualidade dos frutos, reduzindo a concentração de sólidos solúveis totais, aumentando a acidez total e o brix do suco de plantas cítricas. Não só a qualidade dos frutos é influenciada pela disponibilidade de energia solar e pelo suprimento de água no solo, mas também o rendimento final da cultura é condicionado por essas duas variáveis do meio físico, de modo a afetar a transpiração e a evapotranspiração de espécies frutíferas.

O conhecimento da transpiração a partir da área foliar média do pomar e da evapotranspiração potencial ou de referência pode ser diretamente usado na determinação da quantidade de água a ser aplicada ao solo para suprimento das necessidades hídricas das plantas, principalmente quando se está irrigando o pomar por gotejamento, onde as perdas de água por evaporação são minimizadas. Essa alternativa reduz a variação causada pelo tamanho das árvores e pelos espaçamentos de plantio (Coelho Filho, 2002).

As plantas cítricas apresentam uma capacidade de conservação de água devido à elevada resistência estomática e à cerosidade das folhas. Quando a demanda evaporativa da atmosfera aumenta, os estômatos tendem a fechar, reduzindo as taxas de transpiração. Dessa forma, quando ocorre mudança nas condições ambientais em termos de saldo de radiação e das diferenças entre a pressão de vapor nas folhas e no ar, a planta responde aumentando a resistência estomática. Assim, tem-se verificado comportamento semelhante de demanda de água por plantas cítricas em regiões úmidas e em regiões secas (Coelho Filho et al., 2004).
O consumo anual de água das plantas cítricas varia de 900 a $1.200 \mathrm{~mm}$ (Doorenbos \& Kassam, 1979). No Estado de São Paulo, o consumo de água aproxima-se de 3,0mm.dia ${ }^{-1} \mathrm{em}$ pomares irrigados e de 1,5mm.dia ${ }^{-1}$ naqueles não irrigados (Vieira, 1991). Os dados de diferentes regiões do mundo mostram que o consumo hídrico dos citros no período de inverno é de $1,5 \mathrm{~mm} \cdot$ dia $^{-1}$, e no período de verão é de 3,2 a 4,7mm.dia ${ }^{-1}$ (Boman, 1996). A transpiração de árvores de lima-ácida-Tahiti, estimada pelo método do balanço de calor, nas condições climáticas de Piracicaba-SP, foi, em média, de 90L.planta ${ }^{-1}$. dia $^{-1}$ no verão, e de $36 \mathrm{~L} \cdot$ planta $^{-1} \cdot$ dia $^{-1}$ no inverno, considerando-se plantas com área foliar total de $90 \mathrm{~m}^{2}$ (Marin et al., 2002).

O consumo de água de macieiras é influenciado pela temperatura, pela densidade de fluxo de radiação solar global, pelo déficit de pressão de vapor e pela umidade relativa do ar, sendo que a velocidade do vento apresenta pouco efeito sobre ele. Diferenças no tamanho e na forma das copas causam diferenças significativas na transpiração e na eficiência do uso de água (Li et al., 2002).

Entre os métodos de estimativa da transpiração de árvores frutíferas, destacam-se os que utilizam a medida de fluxo de seiva por fornecimento de calor ao tronco ou ramo. Este método de balanço de calor no caule permite a obtenção do valor diário de fluxo de seiva, o qual equivale à transpiração em espécies arbóreas. Apresenta as vantagens de não necessitar de calibração, de ser não destrutivo e de possibilitar ainda o monitoramento simultâneo da transpiração em muitas plantas. Porém, como desvantagens, podem-se destacar o custo dos sensores comerciais e certa complexidade de manejo, o que dificulta seu uso para fins práticos (Villa Nova et al., 2002; Coelho Filho et al., 2004).

Tem-se tentado estimar a transpiração de frutíferas através do uso de modelos meteorológicos, os quais não exigem a determinação direta das duas resistências envolvidas no cálculo da evapotranspiração de referência (Villa Nova et al., 1999) ou por intermédio de coeficientes lineares que expressam a relação entre a transpiração escalonada pela área foliar, densidade da copa e radiação solar absorvida e a demanda potencial (Angelocci \& Valancogne, 1993; Angelocci, 1996; Braun et al., 2000; Valancogne et al., 2000). Esses modelos simplificam o cálculo da transpiração, sendo dependente apenas do conhecimento da área foliar da cultura e da evapotranspiração de referência, porém sua aplicação é específica para a espécie vegetal e condições meteorológicas em estudo.

Face ao exposto, o presente trabalho teve 
por objetivo propor um método de cálculo do volume de água necessário para uma irrigação com mínimo desperdício em pomares de árvores de lima-ácidaTahiti durante o período de verão, no município de Piracicaba-SP, bem como em pomares de árvores de macieiras durante dois anos de cultivo, em Bordeaux, na região sudoeste da França, considerando-se um menor número de variáveis do meio físico usualmente disponível. Os elementos meteorológicos empregados no método proposto que leva em consideração a eficiência de conversão de energia solar na transpiração das espécies arbóreas, foram: a densidade de fluxo de radiação solar global para citros, e o saldo de radiação e o déficit de saturação de vapor do ar para macieiras. O parâmetro da cultura utilizado como variável de entrada no modelo foi a área foliar.

\section{MATERIAL E MÉTODOS}

\section{Concepção da metodologia proposta}

Define-se como eficiência de conversão de energia solar de um dossel (no caso em particular, árvores de citros) a relação entre a energia utilizada pela árvore no processo da transpiração e a energia radiante disponível interceptada pela mesma em período diurno, ou seja:

$$
\varepsilon=\frac{T M 2,45}{A_{f} Q_{g}}
$$

Na equação (1), os termos significam: $\varepsilon=$ eficiência de conversão de energia solar (adimensional); $\mathrm{TM}=$ transpiração medida ao longo de um dia $\left(\mathrm{L}_{\text {árvore }}{ }^{-1} \mathrm{dia}^{-1}\right)$, convertida em energia $\left(2,45 \mathrm{MJ} \mathrm{L}^{-1}\right) ; \mathrm{A}_{\mathrm{f}}=$ área foliar total da árvore $\left(\mathrm{m}^{2}\right.$ árvore $\left.{ }^{-1}\right) ; \mathrm{Q}_{\mathrm{g}}=$ irradiância solar global incidente no período $\left(\mathrm{MJ} \mathrm{m}^{-2} \mathrm{dia}^{-1}\right)$.

Assim sendo, a eficiência de conversão de energia solar ( $\varepsilon$ ) utilizada pelas plantas cítricas durante o processo transpiratório é um número adimensional que representa o quanto da energia solar incidente é efetivamente transformada em transpiração (calor latente de vaporização).

$O$ valor de $\varepsilon$ pode ser estimado tanto em função de $\mathrm{Q}_{\mathrm{g}}$ como em função do saldo de radiação $(\mathrm{Rn})$, pois esses elementos meteorológicos caracterizam a energia radiante disponível para o processo de perda d'água sob a forma gasosa por uma comunidade vegetal através dos estômatos. Para as árvores de macieira, $\varepsilon$ foi determinada considerando-se $\mathrm{Rn}$ como a fonte de energia do processo transpiratório, sendo expressa na mesma unidade de $\mathrm{Q}_{\mathrm{g}}$ e definida por:

$$
\varepsilon=\frac{T M 2,45}{A_{f} R n}
$$

\section{Dados experimentais}

A transpiração (TM) foi medida através do método do balanço de calor em pomares de limaácida (Citrus latifolia Tanaka), cv. Tahiti, enxertada sobre limão-cravo com oito anos de idade, bem como de macieira (Malus spp. Linus), cv. Gramanny Smith, enxertada sobre porta-enxerto M-9. Para citros, os dados medidos de transpiração foram obtidos por Marin (2000) em pomares irrigados com superfícies foliares de 99 e $48 \mathrm{~m}^{2}$, sob espaçamento de $8,0 \mathrm{x}$ 5,0 $\mathrm{m}$ e plantio efetuado no início de janeiro (estação chuvosa), no município de Piracicaba-SP. Para macieiras, os dados medidos de transpiração foram coletados por Angelocci (1996), na região sudoeste da França para diferentes épocas dos anos agrícolas de 1988 e 1989 em pomares irrigados com áreas foliares de 4,7; 7,8; 9,3;11,3; 15,7 e 20,6 $\mathrm{m}^{2}$.

A densidade de fluxo de radiação solar global $\left(\mathrm{Q}_{\mathrm{g}}\right)$ foi medida com um piranômetro Eppley - modelo PSP, e o saldo de radiação (Rn), com um saldo radiômetro - modelo Zipp \& Zonen, sendo ambas as variáveis do meio físico registradas por um sistema de aquisição de dados, modelo datalogger CR1000, da marca Campbell Scientific Inc. A área foliar foi medida por intermédio de um medidor de área foliar, da marca LICOR, para ambas as espécies frutíferas, nas localidades mencionadas.

Uma estação meteorológica automatizada completa (EMA), da marca Campbell Scientific Inc., foi instalada nos pomares de citros e macieiras, visando ao monitoramento em base diária de temperatura do ar, umidade relativa do ar, densidade de fluxo de radiação solar global, saldo de radiação, precipitação, velocidade e direção do vento, durante o período correspondente às safras agrícolas das espécies arbóreas cultivadas nas regiões estudadas. Assim, em função dos dados médios diários de temperatura e umidade relativa do ar, calculou-se o valor da média do déficit de saturação de vapor do ar $(\Delta \mathrm{e})$, considerando-se a equação de Tetens para a obtenção da pressão de saturação de vapor à temperatura média diária do ar (Pereira et al., 1997).

\section{Análise estatística}

Estudou-se a relação de dependência entre o parâmetro eficiência de conversão de energia solar em taxas de transpiração $(\varepsilon)$ e a densidade de fluxo de radiação solar global diária $\left(\mathrm{Q}_{\mathrm{g}}\right)$ em árvores de citros cultivadas sob as condições climáticas do município de Piracicaba-SP. Para tanto, procedeu-se 
a estudo de regressão linear simples entre ambas as variáveis, utilizando-se do conjunto de dados diários de transpiração medida para proposição do modelo de regressão (Janeiro de 2000, n = 17). Outra série independente de dados foi considerada para testar a viabilidade de utilização da metodologia de cálculo do consumo hídrico de plantas cítricas em função da área foliar $\left(\mathrm{A}_{\mathrm{f}}\right)$ e de $\mathrm{Q}_{\mathrm{g}}$ (Fevereiro de 2000, $\mathrm{n}=23$ ). $O$ teste de verificação da viabilidade da metodologia deu-se mediante comparação entre valores medidos e estimados de transpiração. O mesmo procedimento estatístico foi aplicado aos dados de eficiência de conversão do saldo de radiação $(\mathrm{Rn})$ em taxas de transpiração $(\varepsilon)$ de árvores de macieiras cultivadas na região sudoeste da França. Uma série de dados de transpiração medida foi utilizada para propor a equação de estimativa de $\varepsilon$ em função de Rn (Julho de $1988, \mathrm{n}=12$ ). Outra série independente de dados medidos de transpiração de macieiras foi considerada para o teste do modelo de regressão que permite o cálculo da lâmina de irrigação localizada em função da área foliar $\left(\mathrm{A}_{\mathrm{f}}\right)$, do saldo de radiação $(\mathrm{Rn})$ e do déficit de saturação de vapor médio diário do ar $(\Delta \mathrm{e})($ Julho/Agosto de 1989, $\mathrm{n}=45)$. A precisão das equações de estimativa obtidas foi expressa pelo coeficiente de determinação $\left(\mathrm{R}^{2}\right)$ (Legates \& McCabe, 1999). A exatidão pode ser observada pela dispersão dos pares ordenados compostos por valores medidos e estimados de transpiração ao redor da reta 1:1, a qual foi quantificada pelo índice de concordância (d) (Willmott et al., 1985). Um índice proposto por Camargo e Sentelhas (1995) (c) foi adotado neste trabalho, para indicar o desempenho dos modelos de regressão linear, em associação aos coeficientes de correlação de Pearson (r) e de concordância (d), o qual foi obtido pelo produto entre estes dois últimos parâmetros estatísticos. Para avaliar o erro das estimativas, foram calculados o erro absoluto percentual médio (MAPE) e o erro percentual absoluto suavizado (SAPE), descritos em Goodwin e Lawton (1999).

\section{RESULTADOS E DISCUSSÃO}

\section{Determinação da correlação entre $\varepsilon$ e $Q_{g}$ para pomar de citros}

A Figura 1 demonstra o elevado grau de dependência existente entre $\varepsilon$ e $\mathrm{Q}_{\mathrm{g}}$, expresso pelo coeficiente de determinação de 0,91 . O valor obtido para esse parâmetro estatístico revela que a densidade de fluxo de radiação solar global $\left(\mathrm{Q}_{\mathrm{g}}\right)$ constitui a força motriz dos processos de perda de água através dos estômatos, bem como de fluxo de seiva ao longo dos vasos condutores de plantas cítricas. Observa-se que a relação de dependência entre $\varepsilon$ e $\mathrm{Q}_{\mathrm{g}}$ é expressa por uma correlação negativa e linear entre os limites compreendidos entre 12 e $31 \mathrm{MJ} \mathrm{m}^{-2} \mathrm{dia}^{-1}$.

Assim, verifica-se que a variável $\varepsilon$ pode ser calculada por:

$$
\varepsilon=0,2261-0,0044 Q_{g}
$$

Equação de estimativa da transpiração calculada para citros

A transpiração calculada (TC) foi obtida em função da eficiência de conversão de energia solar $(\varepsilon)$ estimada. Substituindo-se TM por TC na expressão 1 e rearranjando-se os termos dessa equação:

$$
T C=\varepsilon \frac{A_{f} Q_{g}}{2,45}
$$

Substituindo (3) em (4), obtém-se:

$$
\mathrm{TC}=\left(0,0923-0,0018 \mathrm{Q}_{\mathrm{g}}\right) \mathrm{A}_{\mathrm{f}} \mathrm{Q}_{\mathrm{g}}
$$

$\mathrm{Na}$ equação (5), os termos significam: $\mathrm{TC}=$ transpiração (fluxo de seiva) calculada (1 árvore $\left.{ }^{-1} \mathrm{dia}^{-1}\right) ; \mathrm{A}_{\mathrm{f}}=$ área foliar $\left(\mathrm{m}^{2} \mathrm{de}\right.$ folha árvore $\left.^{-1}\right) ; \mathrm{Q}_{\mathrm{g}}=$ densidade de fluxo de radiação solar global $\left(\mathrm{MJ} \mathrm{m}^{-2} \mathrm{dia}^{-1}\right)$.

O teste de verificação da confiabilidade do modelo (equação 5), obtido a partir de uma série independente de dados coletados em pomar de citros, resultou em um coeficiente de determinação de 0,95 , um índice de Willmott de 0,99 e um coeficiente de desempenho de 0,96 (Figura 2).

Os coeficientes $\mathrm{R}^{2}$ e $\mathrm{r}$ trazem informações sobre o grau de precisão; no entanto, nada revelam sobre a exatidão do modelo (Pereira et al., 2003; Pereira \& Villa Nova, 2008). O índice de concordância (d) igual a 0,95 revela uma elevada exatidão, estando em consonância com os valores de d encontrados por Pereira et al. (2003) e Legates e McCabe (1999). O índice de desempenho (c) foi de 0,96 para a localidade e cultura reportadas na Figura 2, indicando um excelente desempenho de acordo com o critério de interpretação descrito por Camargo e Sentelhas (1995). Tanto a precisão do modelo de regressão, dada pela linha de tendência, como a exatidão constatada, expressa pela dispersão dos dados experimentais ao redor da reta de $45^{\circ}$ em gráfico do tipo 1:1, foram consistentes. O valor de c, correspondente a 0,96 , excedeu o valor de índice de concordância considerado como satisfatório reportado pela literatura. Segundo Robinson e Hubbard (1990), o limite inferior aceitável para o índice de concordância (d) é de 0,75 . 
Os valores obtidos para os erros das estimativas expressos pelo MAPE e pelo SAPE foram de $7,4 \%$ e $8,0 \%$, respectivamente, confirmando-se a viabilidade de utilização do método proposto para estimar a transpiração de árvores de citros, na localidade estudada, através da equação 5 .

\section{Determinação da correlação entre $\varepsilon$ e $\Delta \mathrm{e}$ para pomar de macieiras}

A Figura 3 revela a estreita correlação entre $\varepsilon$ e $\Delta$ e, expressa por um coeficiente de determinação de 0,90 . Constata-se, portanto, que a média diária do déficit de saturação de vapor do ar $(\Delta \mathrm{e})$ tem grande influência nos processos de fluxo de seiva e transpiração, em pomar de árvores de macieiras. Observa-se a existência da correlação positiva e linear entre $\varepsilon$ e $\Delta$ e, para valores de déficit médio diário de saturação do ar variando em torno de 0,0 a $2,0 \mathrm{kPa}$. Isso permite inferir que, quanto mais seco estiver o ar atmosférico, maior será a eficiência de utilização do saldo de energia disponível no processo de perda de água de macieiras através dos estômatos. A transpiração é tida como processo que consome energia do meio onde as plantas se desenvolvem e somente ocorrerá se houver energia radiante disponível, condicionada ao estabelecimento de um gradiente de pressão de vapor entre a folha e o ar.

Assim, verifica-se que a variável $\varepsilon$ também pode ser calculada por:

$$
\varepsilon=0,2462+0,0703 \Delta \mathrm{e}
$$

\section{Equação de estimativa da transpiração calculada para macieiras}

O valor da transpiração calculada (TC) será determinado substituindo-se TM por TC na equação (2) empregada para se calcular $\varepsilon$. Assim sendo, tem-se:

$$
T C=\frac{\varepsilon R_{n} A_{f}}{2,45}
$$

Substituindo (6) em (7), tem-se que:

$$
T C=\frac{(0,2462+0,0703 \Delta e) R_{n} A_{f}}{2,45}
$$

Ou ainda simplificando,

$$
T C=(0,1+0,0287 \Delta \mathrm{e}) \mathrm{Rn} \mathrm{A}_{\mathrm{f}}
$$

A equação (8) expressa, então, o método da "eficiência de conversão de energia solar" proposto para avaliação da transpiração de macieiras, onde os termos significam: $T C=$ transpiração calculada ( $\mathrm{L}$ árvore ${ }^{-1}$ dia $\left.^{-1}\right) ; \Delta e=$ déficit de saturação de vapor médio diário do ar $(\mathrm{kPa}) ; R n=$ saldo de radiação $\left(\mathrm{MJ} \mathrm{m}^{-2} \mathrm{dia}^{-1}\right) ; A_{f}=$ área foliar do dossel $\left(\mathrm{m}^{2}\right.$ árvore $\left.^{-1}\right)$.

A Figura 4 demonstra a relação de dependência entre a transpiração medida pelo método do fluxo de calor e a transpiração calculada pela equação 8 , com uma precisão expressa por um valor de coeficiente de determinação de 0,99 . Observa-se que há estreita correlação entre os valores medidos e os calculados de transpiração de macieiras, fato que permite destacar a viabilidade de utilização da metodologia de cálculo de lâmina de irrigação localizada em pomares de macieiras com base em informações meteorológicas.

O índice de concordância (d), apresentado na Figura 4, indica elevada exatidão do modelo de regressão. O índice de desempenho (c) do modelo de 0,99 obtido para estimar a transpiração de árvores de macieira também sobrepujou o limite inferior recomendado por Robinson e Hubbard (1990). Os valores do erro das estimativas calculados foram muito baixos e semelhantes àqueles encontrados para citros, tendo sido MAPE e SAPE correspondentes a $8,1 \%$ e $7,9 \%$, respectivamente. Os parâmetros estatísticos considerados confirmam a confiabilidade do método proposto para a cultura e localidade ilustradas na Figura 4.

Em estudos futuros desenvolvidos com a cultura da macieira, sugere-se definir a eficiência de uso da energia líquida disponível no processo transpiratório em função da densidade de fluxo de radiação solar global, a qual é usualmente medida em postos de observação de superfície. Isto facilitaria as aplicações agrícolas com vistas à maximização da produção de pomares de macieiras com proteção ambiental em dado local, além de dispensar informações referentes ao regime de temperatura, umidade relativa e média do déficit de saturação de vapor do ar. 


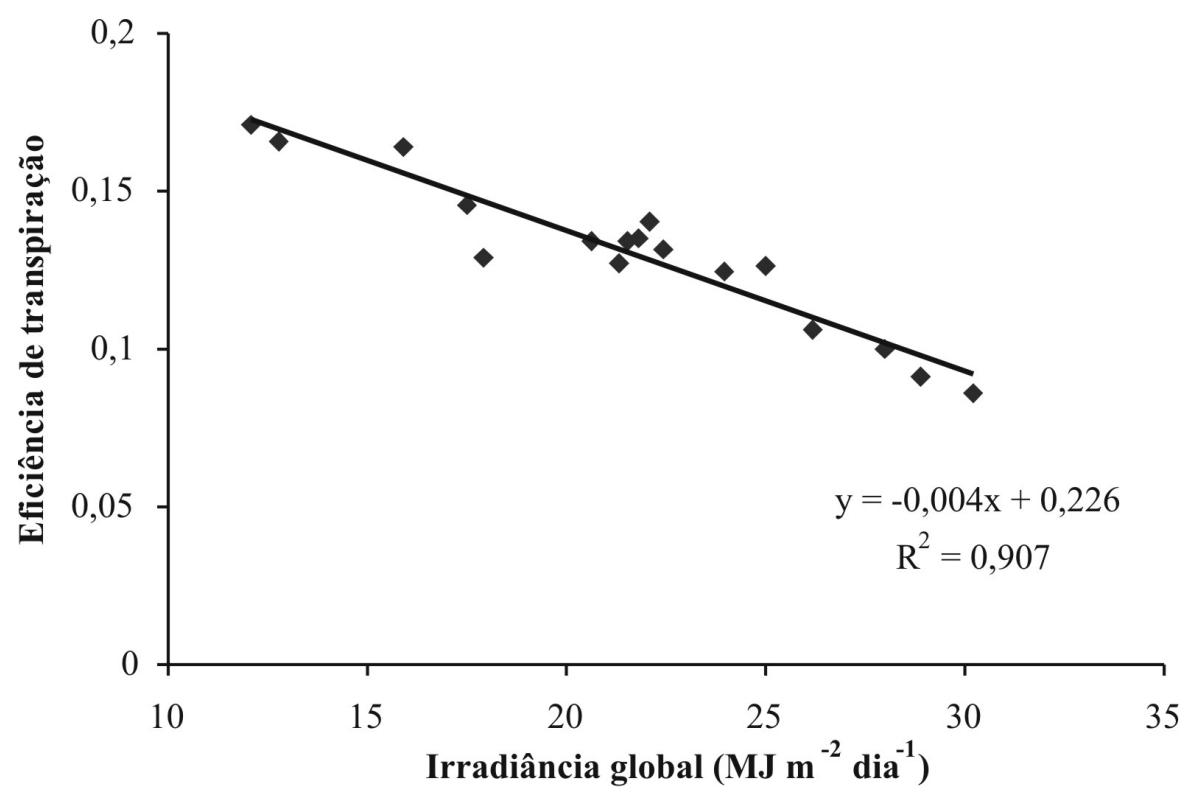

FIGURA 1 - Relação de dependência entre eficiência de conversão de energia solar de plantas cítricas e a densidade de fluxo de radiação solar global. Piracicaba-SP, 2000

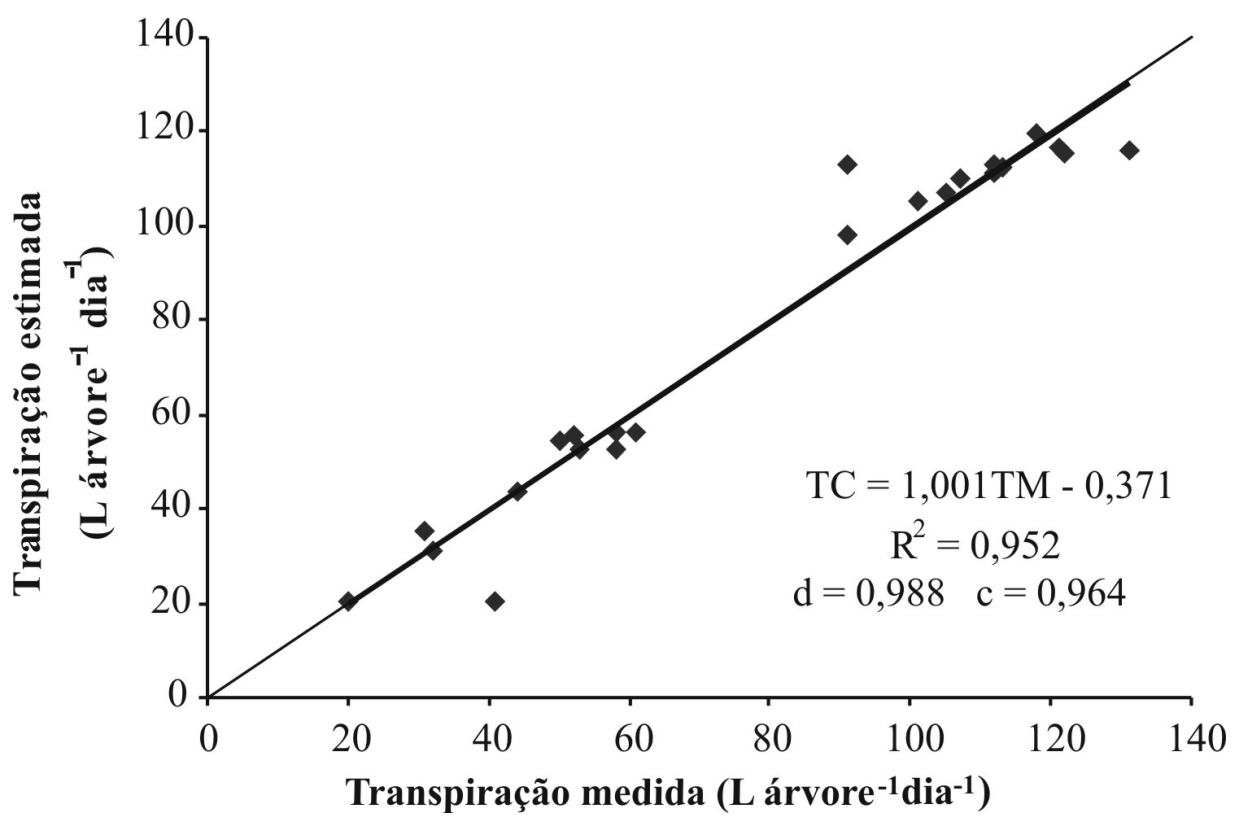

FIGURA 2 - Relação de dependência entre a transpiração estimada pelo método proposto e a transpiração medida de plantas cítricas, em litros, por árvore por dia, considerando-se uma série independente de dados experimentais coletados em Piracicaba-SP, 2000. 


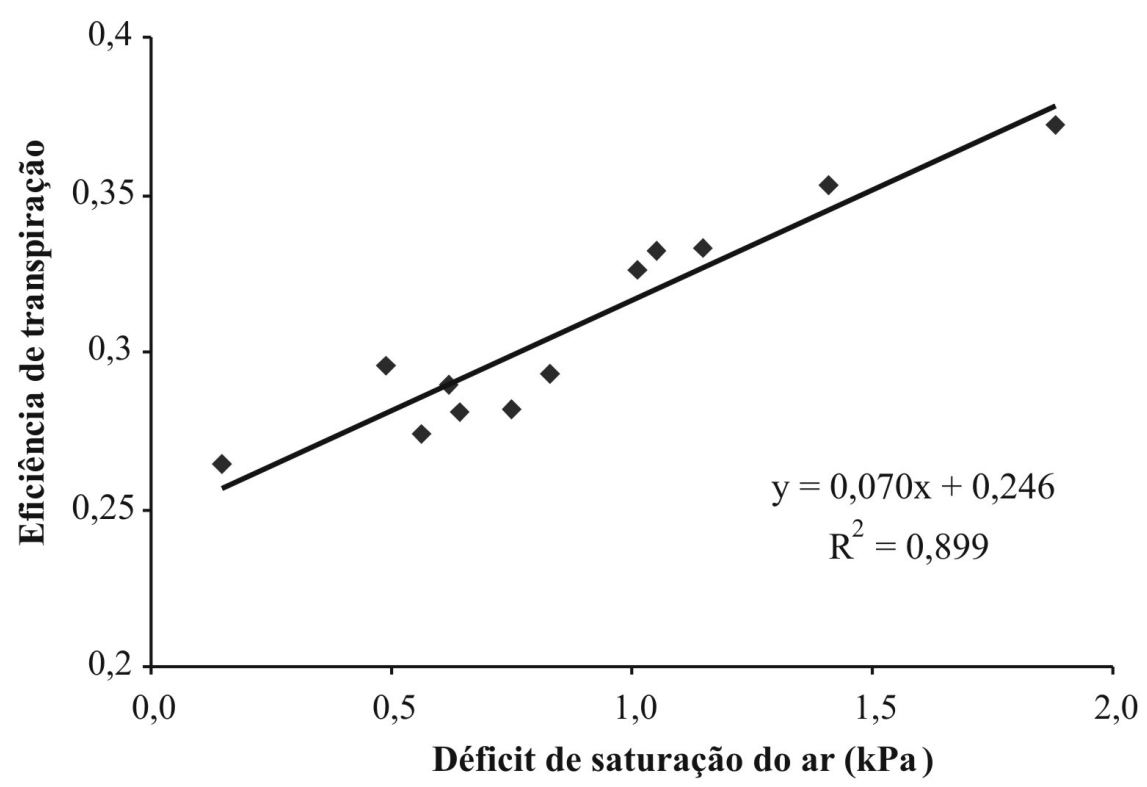

FIGURA 3 - Relação entre a eficiência de conversão de saldo de radiação de árvores de macieiras e o déficit médio diário de saturação de vapor do ar. Bordeaux, na região sudoeste da França, 1988-1989.

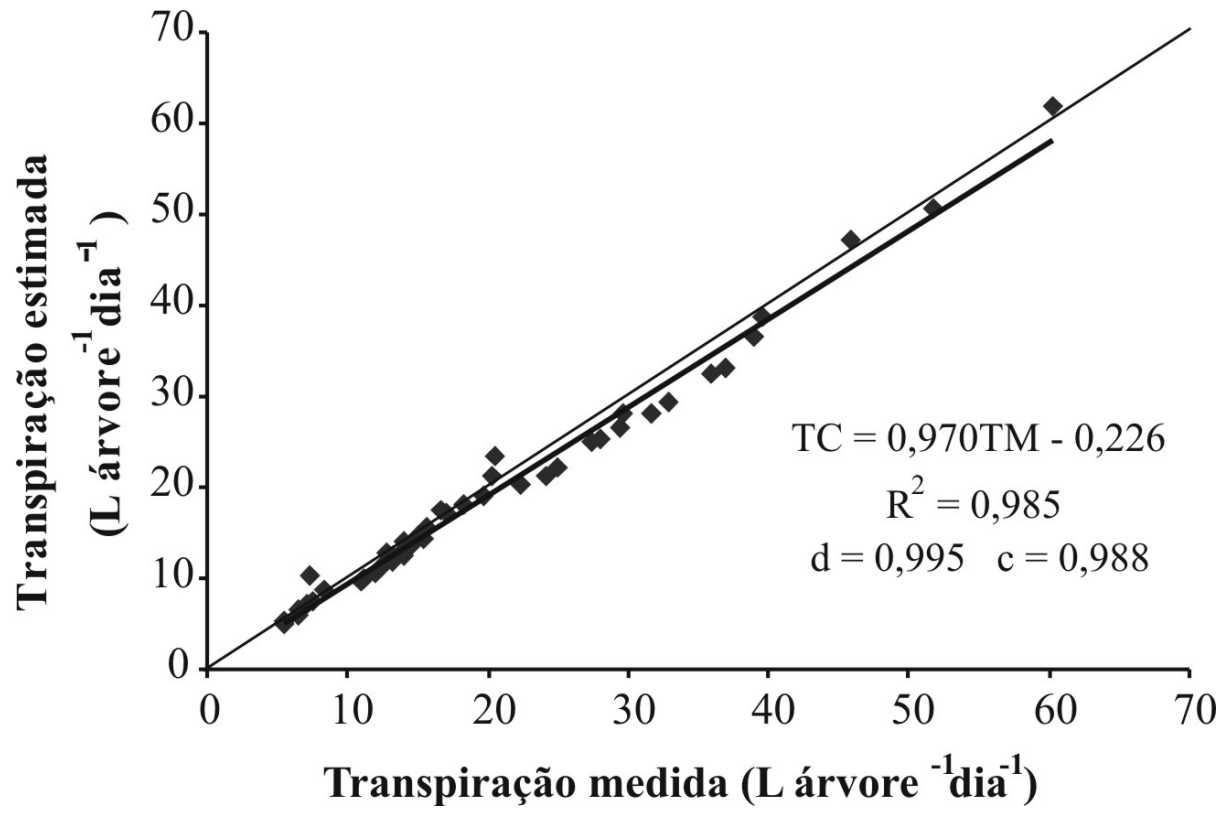

FIGURA 4 - Comparação entre a transpiração estimada pelo método proposto e a transpiração medida de árvores de macieiras, em litros por árvore por dia, considerando-se uma série independente de dados experimentais coletados em Bordeaux, na região sudoeste da França, 1988-1989. 


\section{CONCLUSÕES}

1-A transpiração de plantas cítricas pode ser estimada com alta precisão a partir da área foliar e da irradiância solar global. O único dado meteorológico requerido é usualmente medido em estações meteorológicas e é de conhecimento regional, o que torna o método proposto bastante viável tanto para procederse ao planejamento e à condução da irrigação, como para avaliações preliminares de projeto.

2-A transpiração de árvores de macieiras pode ser estimada com alta precisão a partir da área foliar, do saldo de radiação e do déficit de saturação do ar.

3-O método proposto constitui um procedimento de cálculo das lâminas de irrigação localizada em pomares de plantas cítricas e árvores de macieiras, sendo recomendado para as regiões estudadas, desde que seja calibrado por intermédio de medidas lisimétricas ou pelo emprego do método do balanço de calor.

\section{AGRADECIMENTOS}

Os autores agradecem à ESALQ/USP e à EMBRAPA/Instrumentação, pela concessão dos dados experimentais, bem como ao CNPq, pela bolsa de produtividade em pesquisa, $\mathrm{PQ}-1 \mathrm{~B}$, concedida ao segundo autor do presente estudo.

\section{REFERÊNCIAS}

ANGELOCCI, L.R.; VALANCOGNE, C. Leaf area and water flux in apple trees. Journal of Horticultural Science, London, v.67, n.2, p.299-307, 1993.

ANGELOCCI, L.R. Estimativa da transpiração máxima de macieiras (Malus spp) em pomares pelo método de Penman-Monteith. 1996. 95 f. Tese (Livre-Docência) - Escola Superior de Agricultura "Luiz de Queiroz", Universidade de São Paulo, Piracicaba, 1996.

BRAUN, P.; MAURER, B.; HEINEMANN, G. Scaling transpiration in apple orchards - meteorological versus plant based physiological measurements. Acta Horticulturae, The Hague, v.537, n.1, p.45$51,2000$.

BOMAN, B. Citrus: understanding its irrigation requirements. Irrigation Journal, Heidelberg, v.16, n.2, p.8-11, 1996.
CAMARGO, A.P.; SENTELHAS, P.C. Avaliação de modelos de estimativa da evapotranspiração potencial mensal em base diária para Campinas e Ribeirão Preto-SP. In: CONGRESSO BRASILEIRO DE AGROMETEOROLOGIA, 7., 1995. Anais... Campina Grande: SBA, 1995. p.415-417.

COELHO FILHO, M.A. Determinação da transpiração máxima em pomar jovem de lima-ácida 'Tahiti' (Citrus latifólia Tan.) e sua relação com a evapotranspiração de referência. $2002.91 \mathrm{f}$. Tese (Doutorado em Irrigação e Drenagem)- Escola Superior de Agricultura "Luiz de Queiroz", Universidade de São Paulo, Piracicaba, 2002.

COELHO FILHO, M.A.; ANGELOCCI, L.R.; ROJAS, J.S.D.; CAMPECHE, L.F.S.M.; FOLEGATTI, M.V. Relações entre a transpiração máxima, área foliar e evapotranspiração de referência em pomar jovem de lima-ácida-Tahiti. Revista Brasileira de Agrometeorologia, Piracicaba, v.12, n.2, p.265-274, 2004.

COELHO, E.F.; MAGALHÃES, A.F.J.; COELHO FILHO, M.A. Irrigação e fertirrigação em citros. Cruz das Almas: EMBRAPA, 2004. 16 p. (Circular Técnica, 72)

DOORENBOS, J.; KASSAM, A.H. Yield response to water. Rome: FAO, 1979. 193p. (Irrigation and Drainage Paper, 33)

GOODWIN, P.; LAWTON, R. On the asymmetry of the symmetric MAPE. International Journal of Forecasting, Oxford, v.15, n.2, p.405-408, 1999.

LEGATES, D.R.; McCABE JR., G.J. Evaluating the use of "goodness-of-fit" measures in hydrologic and hydroclimatic model validation. Water Resources Research, Amsterdam, v.35, n.1, p.233-241, 1999.

LI, F.; COHEN, S.; NAOR, A.; SHAOZONG, K.; EREZ, A. Studies of canopy structure and water use of apple trees on three rootstocks. Agricultural Water Management, Amsterdam, v. 55, n.1, p.114, 2002.

MARIN, F.R. Evapotranspiração, transpiração e balanço de energia em pomar de lima-ácida 'Tahiti'. 2000. 73 f. Dissertação (Mestrado em Irrigação e Drenagem) )- Escola Superior de Agricultura "Luiz de Queiroz", Universidade de São Paulo, Piracicaba, 2000. 
MARIN, F.R.; ANGELOCCI, L.R.; PEREIRA, A.R.; VILLA NOVA, N.A.; SENTELHAS, P.C. Balanço de energia e consumo hídrico em pomar de lima-ácida 'Tahiti'. Revista Brasileira de Meteorologia, São Paulo, v.17, n.2, p.219-228, 2002.

PEREIRA, A.B.; VILLA NOVA, N.A.; GALVANI, E. Estimation of global solar radiation flux density in Brazil as a function of a single measurement at solar noon. Biosystems Engineering, Edinburg, v.86, n.1, p.27-34, 2003.

PEREIRA, A.B.; VILLA NOVA, N.A. Potato maximum yield as affected by crop parameters and climatic factors in Brazil. HortScience, North Carolina, v.43, n.5, p.1611-1614, 2008.

PEREIRA, A.R.; ANGELOCCI, L.R.; SEDIYAMA, G.C. Evapotranspiração. Piracicaba: FEALQ, 1997. 183p.

ROBINSON, J.M.; HUBBARD, K.G. Soil water assessment model for several crops in high plains. Agronomy Journal, Madison, v.82, n.4, p.11411148, 1990.

VALANCOGNE, C.; DAYAU, S.; PIERI, P.; FERREIRA, M.I.; SILVEIRA, J.; ANGELOCCI, L.R. Influence of orchard and vineyard characteristics on maximal plant transpiration. Acta Horticulturae, The Hague, v.537, p.61-68, 2000.
VIEIRA, D.G. Irrigação de citros. In: RODRIGUES, O.; VIEGAS, F.; POMPEU JUNIOR, J.; AMARO, A.A. Citricultura brasileira. 2.ed. Campinas: Fundação Cargill, 1991. p.519-541.

VILLA NOVA, N.A.; ANGELOCCI, L.R.; PEREIRA, A.R. Estimativa da transpiração máxima de macieiras em pomares irrigados pelo método da advecção-aridez adaptado. In: CONGRESSO BRASILEIRO DE AGROMETEOROLOGIA, 11., 1999. Anais... Florianópolis: SBA, 1999. (CD-ROM).

VILLA NOVA, N.A.; ANGELOCCI, L.R.; VALANCOGNE, C.; SENTELHAS, P.C.; PEREIRA, A.R.; MARIN, F.R. Estimativa da transpiração máxima de macieiras, em pomares irrigados, pelo método de Penman adaptado. Revista Brasileira de Agrometeorologia, Santa Maria, v.10, n.2, p.245-250, 2002.

WILLMOTT, C.J.; ACKLESON, S.G.; DAVIES, R.E.; FEDDEMA, J.J.; KLINK, K.M.; LEGATES, D.R.; O'DONNELL J.; ROWE, C.M. Statistics for the evaluation and comparison of models. Journal of Geophysical Research, Washington, v.90, n.5, p.8995-9005, 1985. 